Healthcare and Biomedical Technology in the 21st Century 

George R. Baran - Mohammad F. Kiani Solomon Praveen Samuel

\section{Healthcare and Biomedical Technology in the 21st Century}

An Introduction for Non-Science Majors

Springer 
George R. Baran

College of Engineering

Temple University

Philadelphia, PA, USA

Solomon Praveen Samuel

Orthopedic Surgery Bioengineering

Laboratory

Albert Einstein Medical Center

Philadelphia, PA, USA
Mohammad F. Kiani

Department of Mechanical Engineering

Temple University

Philadelphia, PA, USA

ISBN 978-1-4614-8540-7

ISBN 978-1-4614-8541-4 (eBook)

DOI 10.1007/978-1-4614-8541-4

Springer New York Heidelberg Dordrecht London

\section{Library of Congress Control Number: 2013947470}

(C) Springer Science+Business Media New York 2014

This work is subject to copyright. All rights are reserved by the Publisher, whether the whole or part of the material is concerned, specifically the rights of translation, reprinting, reuse of illustrations, recitation, broadcasting, reproduction on microfilms or in any other physical way, and transmission or information storage and retrieval, electronic adaptation, computer software, or by similar or dissimilar methodology now known or hereafter developed. Exempted from this legal reservation are brief excerpts in connection with reviews or scholarly analysis or material supplied specifically for the purpose of being entered and executed on a computer system, for exclusive use by the purchaser of the work. Duplication of this publication or parts thereof is permitted only under the provisions of the Copyright Law of the Publisher's location, in its current version, and permission for use must always be obtained from Springer. Permissions for use may be obtained through RightsLink at the Copyright Clearance Center. Violations are liable to prosecution under the respective Copyright Law.

The use of general descriptive names, registered names, trademarks, service marks, etc. in this publication does not imply, even in the absence of a specific statement, that such names are exempt from the relevant protective laws and regulations and therefore free for general use.

While the advice and information in this book are believed to be true and accurate at the date of publication, neither the authors nor the editors nor the publisher can accept any legal responsibility for any errors or omissions that may be made. The publisher makes no warranty, express or implied, with respect to the material contained herein.

Printed on acid-free paper

Springer is part of Springer Science+Business Media (www.springer.com) 


\section{Welcome}

\section{Dear Student,}

Congratulations on having enrolled in this class! We don't know how you feel about engineering and science, or healthcare biotechnology in particular, but our promise to you is that everything you learn here will be useful to you for the rest of your life. It may take you more than one semester to realize that, but the moment will come.

We all know that at some point you or someone you care about will be in need of medical attention and treatment. That will be a difficult and stressful time, made so in part because you probably won't understand everything that's going on. Developments in healthcare technology are also an important contributing factor to the rising cost of healthcare in the United States, which in all likelihood will be a major economic challenge for your generation. We think that what you learn in this course will demystify some of that medical-speak for you and help you to make decisions about your own healthcare options.

We also suspect that from time to time you get involved in discussions about contemporary topics that are somewhat provocative, e.g., should the sale of highsugar-content drinks be regulated; are genetically modified foods safe to eat. How do you argue your point in an intelligent and educated manner? How do you decide which claims make sense and which are nonsense? We're going to provide you with a framework you can use to analyze science-based arguments and develop wellinformed opinions of your own.

In this book, we will introduce you to the healthcare dilemmas facing voters and political leaders everywhere and discuss what makes the scientific method so useful in arriving at decisions based on data analysis. We will expose you to the ethical questions that scientists and policy makers consider when assessing the cost and value of scientific progress, the pros and cons and ethics of performance-enhancing drugs, and how new drugs and devices are developed and approved for sale in the United States, covering topics such as animal testing, human clinical trials, and the patent system. 
We will then relive the experience of a visit to a doctor and discuss the various tests and methods used to arrive at a diagnosis, explaining some of the core technologies that enable the sophisticated analytical methods used today. If you or a member of your family has ever needed a tissue or organ replaced, the chapter on implants will provide plenty of background information about the materials used, the way the human body reacts to implants, and you will read case studies that will help you realize how medical treatment decisions are made.

It's likely that someone in your family has suffered from heart disease; in the chapter on cardiovascular devices, we will explore heart anatomy and physiology, and you will learn the how and why of pacemakers, defibrillators, and artificial hearts. We will examine the clever strategies behind the development of new cancer-fighting drugs and how they are to be administered, as well as the techniques used by drug manufacturers to ensure that pills and tablets are designed to get the drug safely to its destination. Our focus on molecules will continue as we discuss the new and emerging field of tissue engineering, when biochemical cues are used to grow human tissue in the lab for eventual use as repair materials, and expose you to the promises and dangers of genetic engineering of crops and animals, and of our own cells to arm them for battle with disease.

In closing, we will describe a visit to the dentist and obtain a better understanding of the tools and procedures used to keep mouths healthy and functional, and how dentists can repair oral tissues when they are lost to decay or require adjustment for other reasons. In the last chapter, we will present an overview of the technology available to aid the disabled live as "normal" a life as possible.

At the end of each chapter, we list what we think are the most important concepts we have presented. These should be helpful to you as you reread and review the chapter and also provide topics for discussion.

We hope very much that your instructor will encourage questions and debate in class. Throughout several chapters we have highlighted questions that we hope will stimulate you to think about these timely topics. Scientists argue all the time, why shouldn't you? It's good practice to question authority and the "accepted" explanation. It will quickly become obvious who can make the stronger case, and arguments will help to clarify your thoughts.

Finally, we realize that science or engineering may not necessarily be your future chosen profession. But, if after finishing this course you leave thinking that the scientific method of rational thinking, evidence-based judgment, and peer review make a lot of sense, then do us all a favor and run for political office! 


\section{Preface}

\section{Dear Instructor,}

We are delighted that you have chosen our book for your course! Let us tell you how the book came to be, and what our guiding philosophy has been during its development.

"Healthcare and Biotechnology in the 21st Century" resulted from our experiences participating in Temple University's General Education curriculum. Every Temple undergraduate student is required to take four courses in subjects outside their major. For example, all non-science and non-engineering majors are required to take two courses in science or technology and two courses in mathematics (numerical proficiency). We decided to institute a new course covering medical technology (our own field of expertise) that would draw on basic biologic, physics, chemistry, and engineering principles, discuss the scientific method, gently underline the value of a quantitative approach to life, and introduce and explain medical technologies that our students or their family members are likely to have encountered as patients.

Our search for an appropriate textbook made us realize that one did not exist. The available biomedical texts were all written for science or engineering majors. We decided to write our own course-pack, and have been using it for several years. The opportunity eventually came along for us to devote some additional time to revising the course pack, and to compile a book on these topics. Discussions with colleagues and publishers were encouraging, and this volume is the product of a recent surge in writing and editing activity.

We want to emphasize that the book is designed for use in an undergraduate-level course taught to non-science, non-engineering majors: students who are likely to have graduated high school convinced that they would never have to take another science course again, who probably did not take more than the minimum number of science courses in high school, and many who may consider their participation in this course to be a waste of time.

In planning this book, we were fully cognizant of research indicating that students not majoring in the sciences or engineering would not profit (learn) from a 
traditional science or engineering textbook. Instead, we have presented overviews of the developments in biomedical technology, attempting to engage students in scientific and critical thinking. Our reasoning is that although the specific biomedical areas we cover will develop during the students' lifetimes, learning about evidence-based argumentation, peer review, and the inquiry-driven scientific method will stand the students in good stead for many more years.

That's why we have also tried to write the book in a language these students should understand. It's not the language used to communicate with scientists via a manuscript, but students who make an effort to broaden their vocabulary should have little difficulty following the text.

The first portion of the book introduces healthcare policy and its ramifications for the future, discusses how scientists and engineers think and work, shows how science impacts daily life, reveals how medical biotechnology is regulated in the United States, provides an introduction to a few of the technologies that enable modern health care biotechnology, and ends with a description of the events that can occur during a visit to a doctor. In some of the chapters we ask questions designed to encourage student involvement; the answers are not always obvious, and do not require prior scientific knowledge, but provide an opportunity for the instructor to guide discussion according to scientific principles. Feel free to use them or come up with new ones. And yes, we do have a point of view on certain hot-button issues, and that point of view may become obvious to the reader; if you don't agree with it, there's a great opportunity for a classroom debate! We do make an effort to present some alternative views, but emphasize prevailing scientific or data-driven opinions.

That foundation sets the stage for the second portion of the book, where we focus on specific healthcare biotechnologies, with some case histories mixed in to illustrate our points. This is where students will encounter the most "science" information. We realize that each instructor will tailor the amount of material that is taught to the level of the student body. With that in mind, we will advise that portions of Sects. 7.2 and 7.4-7.7 in Chap. 7 may prove difficult for students with poor backgrounds in science and mathematics. Chapters 10 and 12 contain vocabulary that may be unfamiliar to students who have not had prior courses in biology, and the instructor may wish to devote extra time to vocabulary development. Students will need to know the meanings of the words if they are to understand the concepts being presented.

The book is lengthy, and not all the topics can be covered in depth during a typical 14-15-week semester. Feel free to pick and choose according to your interests and your student body, and good luck with the course! 


\section{Acknowledgements}

We wish to acknowledge contributions to the text made by:

Ken Boberick, D.M.D.

John A. Handal, M.D.

Thomas K. John, M.D.

Salim Merali, Ph.D.

Bin Wang, Ph.D.

We also thank Ms. Jessica Welhaf for original drawings and illustrations.

The contributors of other images are acknowledged directly in the text.

George Baran wishes to thank the staff of The Department of Bioengineering, The Imperial College London, for their hospitality during his leave.

Note: The inclusion of images of proprietary products or citations of specific products or brand names does not constitute an endorsement of these products by the authors. 



\section{Contents}

\section{Is Technology the Cure for Soaring Demand}

and the High Costs of Healthcare? ..................................................... 1

1.1 Introducing the Problem: Healthcare Statistics and Insurance ........ 1

1.1.1 The Global Picture ............................................................... 2

1.1.2 Comparing and Evaluating Quality of Healthcare and Its Implications........................................................... 4

1.1.3 Costs of Healthcare................................................................... 6

1.2 New Technologies...........................................................................

1.3 Bringing Down Healthcare Costs: Electronic Medical Records...... 9

1.4 International Aspects of Healthcare Technology

Development and Adoption .......................................................... 11

1.5 Progress in Healthcare Technology................................................. 13

1.6 Is Progress in Technology the Best Answer
for Improving Health? ..................................................................

1.7 Foundation Concepts …………………………............................... 17

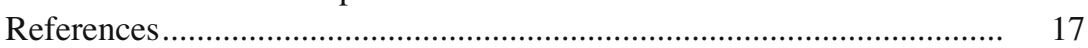

2 Science, Pseudoscience, and Not Science: How Do They Differ? ....... 19

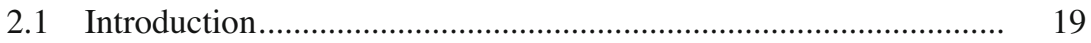

2.2 Popular Views and Public Perception of Science ........................... 20

2.3 Student Attitudes About Science........................................................ 22

2.4 How Science Is "Done" .................................................................. 23

2.4.1 How Scientific Ideas Beget Scientific Research................. 24

2.4.2 Collecting More Data to Validate a Theory:
Who Pays for Science and Engineering Research............... 28

2.4.3 Announcing Research Results: Scrutiny by Peers ............... 29

2.4.4 Theories and Laws ............................................................. 31

2.4.5 What Can Go Wrong in the Scientific Process ................... 33

2.4.6 Pseudoscience .................................................................. 38

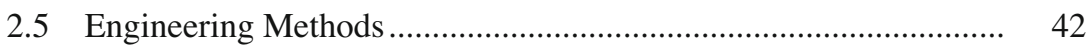

2.6 Science and Religion (Nonscience) …………………………......... 44 
2.7 Science and Politics ........................................................................ 47

2.8 Scientifically Based Arguments ................................................... 48

2.9 Analyzing Pseudoscientific Claims .............................................. 50

2.10 Summary .......................................................................... 55

2.11 Foundational Concepts.................................................................. 56

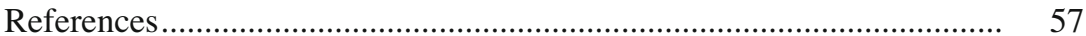

3 Technology and Bioethics: What Can Scientists and Engineers

Do and What Should They Do? ....................................................... 59

3.1 Introduction.............................................................................. 60

3.2 A History of Bioethics................................................................. 60

3.3 End of Life: The Integration of Technology, Law, Individual Rights, and Religious Belief.......................................... 63

3.3.1 Technologies that Sustain/Prolong Life .............................. 63

3.3.2 End-of-Life Case Study...................................................... 67

3.3.3 End-of-Life Planning and Care .......................................... 68

3.3.4 Death ....................................................................... 71

3.4 Patients' Rights: Should They Be Told Everything?..................... $\quad 72$

3.5 Physicians' Dilemmas: Who Gets Treatment If Resources Are Limited?.......................................................... $\quad 77$

3.6 Biotechnologies with Potential Ethical Issues:

3.6.1 Neurotechnology .......................................................... 79

3.6.2 Genetic Testing................................................................. 80

3.6.3 Reproductive Biotechnologies .......................................... 81

3.6.4 Organ and Tissue Transplantation ........................................ 83

3.6.5 Stem Cells ................................................................... 87

3.7 Human Enhancement: I Want to Be Better ................................... 89

3.7.1 Enhancing Athletic Performance........................................ 89

3.7.2 Cognitive Enhancement .................................................. 92

3.7.3 Enhancing the Ability to Work........................................... 94

3.7.4 Enhancing Appearance...................................................... 95

3.8 Summary .............................................................................. 97

$3.9 \quad$ Foundational Concepts................................................................... 98

References.......................................................................... 99

4 Inventing, Evaluating, and Approving New Drugs and Devices......... 101

4.1 Introduction............................................................................. 102

4.1.1 Ideas for New Technologies.............................................. 102

4.1.2 The Patent Process .......................................................... 103

4.1.3 To Market, to Market... .................................................... 106

4.2 Dealing with the Regulators ......................................................... 108

4.2.1 The FDA.................................................................... 109

4.2.2 Getting a Drug Approved .................................................. 114

4.2.3 Getting a Medical Device Approved:
A Somewhat Different Process ......................................... 116 
4.3 Use of Animals in Biomedical Research ................................... 118

4.4 Use of Humans in Research.................................................... 120

4.5 Postmarket Surveillance: How Do Products Perform Years After They Have Been Sold?

4.6 Room for Improvement: What Can Be Done to Increase Reliability and Utility of Clinical Trials?.................. 126

4.7 Manufacturer-Consumer-FDA Relations .................................. 128

4.8 Case History: Silicone Breast Implants .................................... 131

4.9 Summary ............................................................................... 132

4.10 Foundational Concepts................................................................ 133

References........................................................................... 134

5 A Visit to the Physician: Diagnoses and Enabling Technologies ....... 137

5.1 Introduction....................................................................... 137

5.2 Home or Self-Diagnosis.......................................................... 138

5.3 The Beginning of a Visit to the Doctor ..................................... 140

5.4 Beyond the Physical Exam: Blood Tests .................................... 143

5.5 Heart Function ...................................................................... 146

5.6 Gender-Specific Diagnostic Tests ............................................. 149

5.7 So Many Tests......................................................................... 149

5.8 Medical Imaging .................................................................. 151

5.8.1 Imaging Basics ............................................................. 152

5.8.2 X-Ray Imaging............................................................. 154

5.8.3 Nuclear Imaging..................................................... 156

5.8.4 Imaging with CAT Scanners ....................................... 157

5.8.5 Health Concerns with X-Rays....................................... 159

5.8.6 Ultrasound Imaging...................................................... 160

5.8.7 Magnetic Resonance Imaging ....................................... 163

5.8.8 MRI Versus CT Scan.................................................... 164

5.8.9 Contrast Agents ............................................................ 166

5.9 Getting Small: Micro- and Nanotechnology............................... 167

5.9.1 How Microelectronic Devices Are Made......................... 167

5.9.2 Biosensors ................................................................... 169

5.9.3 Nanotechnology; Getting Smaller Still .......................... 172

5.9.4 Matter at the Nanoscale................................................. 175

5.9.5 Hybridizing Imaging with Other Technologies................ 177

5.10 Summary ................................................................... 181

5.11 Foundational Concepts......................................................... 181

References.................................................................. 182

6 Properties of the Host (The Human Body) ......................................... 183

6.1 Introduction....................................................................... 183

6.2 Cells: The Basic Building Blocks of Tissues in the Body ........... 184

6.2.1 Cell-Surface Interactions .............................................. 186

6.2.2 The Defensive Systems of the Human Body ................... 188 
6.2.3 Other Implant-Host Interactions ...................................... 190

6.2.4 The Wound Healing Response ........................................ 191

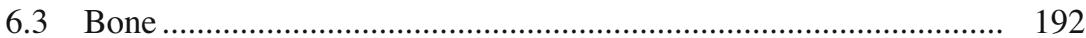

6.3.1 Bone Structure ................................................................ 192

6.3.2 Bone Activity ........................................................... 195

6.3.3 Bone Degradation and Fracture ......................................... 196

6.4 Diseases of the Joints: Arthritis.................................................. 199

6.5 Summary ................................................................................. 200

6.6 Foundational Concepts................................................................ 201

References...................................................................... 202

\section{Properties and Behavior of Materials and Some Design}

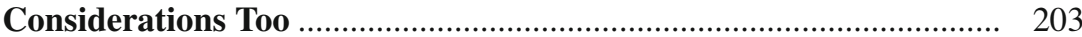

7.1 Introduction.................................................................... 203

7.2 Types of Synthetic Materials.................................................... 204

7.2.1 Metals ............................................................................. 205

7.2.2 Ceramics and Glasses ..................................................... 210

7.2.3 Pyrolytic Carbon........................................................... 213

7.2.4 Polymers ................................................................. 214

7.2.5 Composites ................................................................... 218

7.3 Surface Properties ......................................................................... 219

7.4 Mechanical Behavior of Materials .............................................. 220

7.4.1 Static (No Time Variable Involved) Mechanical Behavior .................................................. 221

7.4.2 Dynamic (Time Is a Variable) Mechanical Behavior
of Materials ............................................................... 229

7.5 Wear ............................................................................. 236

7.6 Material Degradation ............................................................. 238

7.6.1 Corrosion ..................................................................... 238

7.6.2 Polymer Degradation ........................................................ 242

7.7 Designing with Materials ................................................................ 244

7.8 Summary ........................................................................ 245

7.9 Foundational Concepts............................................................. 245

References.............................................................................. 247

8 Biomaterials Applications in Medicine and Case Studies ................... 249

8.1 Introduction...................................................................... 249

8.2 Examples of Implants ................................................................. 249

8.3 Metals in Medicine ................................................................. 257

8.4 Ceramics and Glasses in Medicine ............................................. 259

8.5 Polymers in Medicine ................................................................ 262

8.5.1 Synthetic Polymers ..................................................... 262

8.5.2 Natural Polymers .............................................................. 264

8.6 Surface Modification................................................................. 266

8.7 Antimicrobial Coatings .............................................................. 268

8.8 Designing Medical Devices ...................................................... 271 
8.9 Implant Case Studies.

8.9.1 Case 1: Femoral Bone Fracture Treated

Using Intramedullary Nail.

274

8.9.2 Case 2: Total Knee Replacement

8.9.3 Case 3: Chronic Low Back Pain Treated Using Posterior Lumbar Interbody Fusion (PLIF) Surgery

8.10 Summary

8.11 Foundational Concepts......................................................... 284

References........................................................................... 284

9 Cardiovascular Devices: Getting to the Heart of the Matter............ 287

9.1 Introduction.......................................................................... 287

9.2 Heart Anatomy and Function ................................................... 288

9.3 Malfunctions of the Cardiac Electric System and Remedies........ 291

9.3.1 Arrhythmia ............................................................ 291

9.3.2 Fibrillation................................................................... 294

9.4 Malfunction of the Vascular Network and Remedies .................. 296

9.4.1 Stents and Cardiac Bypass Surgery................................... 296

9.4.2 Intravascular Filters...................................................... 301

9.4.3 Heart Bypass Surgery and Vascular Grafts ..................... 301

9.4.4 Case 1: Traumatic Aortic Rupture Treated Using Endovascular Stent Grafting ......................................... 306

9.4.5 Peripheral Vascular Disease .............................................. 309

9.4.6 Vascular Access Devices ................................................ 310

9.5 Malfunction of Heart Valves and Remedies .............................. 310

9.5.1 Heart Valves .............................................................. 310

9.5.2 Prosthetic Valves ........................................................... 312

9.6 Life-Sustaining Cardiac Devices ............................................... 315

9.6.1 Heart Failure............................................................... 315

9.6.2 Left Ventricular Assist Devices (LVADs) and Artificial Hearts ................................................... 317

9.7 Summary ...................................................................... 320

9.8 Foundational Concepts........................................................ 320

References................................................................... 321

10 Clever Strategies for Controlled Drug Release and Targeted Drug Delivery.......................................................... 323

10.1 Introduction......................................................................... 323

10.2 The Goals of Controlled-Release Systems................................ 324

10.3 The Basic Mechanism of Drug Dispersion: Fick's Law ............... 325

10.4 Advantages and Disadvantages of Targeted Drug-Delivery and Controlled-Release Systems............................................. 327

10.5 Fine-Tuning Drug-Delivery Systems ........................................ 328

10.6 Routes of Drug Administration................................................. 329

10.6.1 Oral Controlled-Release Formulations ......................... 329

10.6.2 Transdermal Controlled-Release Systems...................... 333

10.6.3 Implantable Controlled-Release Systems ..................... 335 
10.6.4 Pulmonary Controlled-Release Systems........................ 336

10.6.5 Parenteral Controlled-Release Systems ........................ 336

10.7 Nanoparticles in Targeted Drug Delivery ................................ 337

10.7.1 Polymers .................................................................. 338

10.7.2 Liposomes.............................................................. 338

10.7.3 Nanotubes .................................................................. 339

10.7.4 Quantum Dots........................................................... 340

10.8 Commercially Available Drug-Delivery Systems..................... 340

10.9 Summary ............................................................................. 341

10.10 Foundation Concepts .......................................................... 341

References.............................................................................. 342

11 Tissue Engineering: Growing Replacement

Human Tissue in the Lab .......................................................... 343

11.1 Introduction .................................................................. 343

11.2 The History of Tissue Engineering ......................................... 345

11.3 Basic Concepts of Tissue Engineering...................................... 346

11.3.1 Cells and Cell Culture................................................... 346

11.3.2 Tissue Engineering Scaffolds .................................... 352

11.3.3 Growth Factors ..................................................... 358

11.3.4 Bioreactors ................................................................ 360

Examples of Engineered Tissue Currently Available
for Patient Treatment........................................................... 360

11.4.1 Tissue Engineering Skin ........................................... 360

11.4.2 Tissue Engineering Cartilage, Bone, Teeth, Tendons, and Muscle................................................................... 363

11.4.3 Tissue Engineering the Heart....................................... 369

11.4.4 Tissue Engineering the Kidney and Bladder ................ 372

11.4.5 Tissue Engineering the Liver...................................... 373

11.4.6 Neural Tissue ............................................................ 375

11.4.7 Case Study 1: Peripheral Nerve Regrowth in the Thumb Using a Collagen Nerve Guide ........................ 376

11.5 The Market for Tissue-Engineered Products:
Has the Promise Been Fulfilled?

11.6 Summary ..................................................................... 379

11.7 Foundational Concepts....................................................... 381

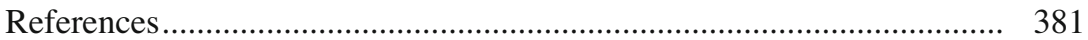

12 Genetic Engineering............................................................ 383

12.1 Introduction: What Is Genetic Engineering? .......................... 383

12.2 The Biochemistry Basis of Genetic Engineering ..................... 384

12.3 How to Introduce Foreign DNA into a Cell: Vectors for Genetic Engineering ....................................................... 392

12.4 Genetic Engineering in Plants and Animals............................ 394

12.5 Genetic Testing: Genomics, Proteomics, and Metabolomics ..... 399 12.5.1 Determining the Genome: Genomics .......................... 401 


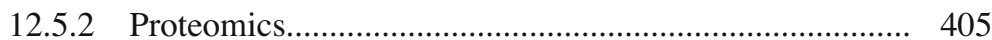

12.5.3 Metabolomics................................................................. 406

12.6 Case Studies Involving Gene Therapy ........................................ 408

12.6.1 Cystic Fibrosis ............................................................. 408

12.6.2 ADA-SCID ................................................................. 409

12.6.3 Ornithine Transcarbamylase Deficiency .......................... 409

12.6.4 HIV..................................................................... 410

12.6.5 Parkinson's Disease ....................................................... 411

12.6.6 Rheumatoid Arthritis...................................................... 411

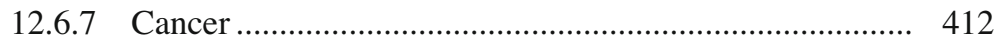

12.6.8 Homozygous Familial Hypercholesterolemia.................. 414

12.7 Summary ...................................................................... 414

12.8 Foundational Concepts................................................................ 415

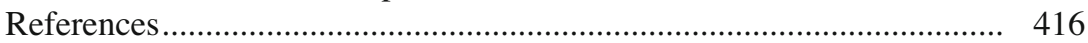

13 A Trip to the Dentist ..................................................................... 417

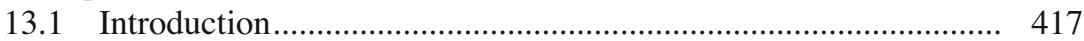

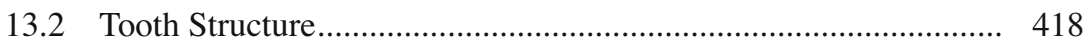

13.3 The Dental Exam ...................................................................... 419

13.3.1 Looking for Decay ......................................................... 419

13.3.2 Other Oral Issues.......................................................... 421

13.4 Dental Treatments with No Tooth Preparation .............................. 424

13.4.1 Tooth Bleaching ........................................................... 424

13.4.2 Tooth Sealants .............................................................. 425

13.5 Restoration of Decayed Teeth ..................................................... 426

13.5.1 Restoring Teeth Using Dental Amalgam ........................ 428

13.5.2 Restoring Teeth Using Dental Composite........................ 430

13.6 Restoration of Badly Damaged or Missing Teeth.......................... 434

13.6.1 Single-Tooth Restoration ................................................ 434

13.6.2 Restoration of Missing Teeth ........................................ 438

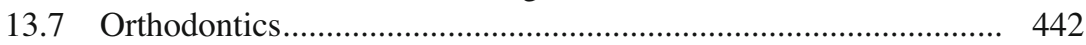

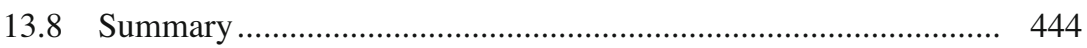

13.9 Foundational Concepts............................................................... 445

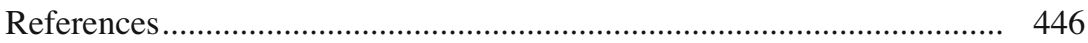

14 Rehabilitation Technologies ........................................................... 447

14.1 Introduction.................................................................... 447

14.2 History of Rehabilitation Medicine ............................................. 450

14.3 Rehabilitating Musculoskeletal Disabilities .................................. 451

14.3.1 Musculoskeletal Pain .................................................. 451

14.3.2 Physical Therapy and Orthoses........................................ 454

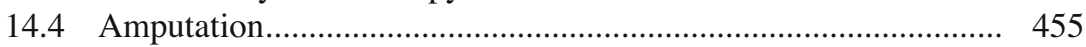

14.4.1 Lower-Extremity Amputation .......................................... 456

14.4.2 Upper-Extremity Amputations ......................................... 460

14.5 Rehabilitating Hearing ................................................................ 462

14.5.1 Cochlear Implants .......................................................... 464

14.5.2 Auditory Brainstem Implant (ABI) ................................. 466 
14.6 Rehabilitating Vision Loss .......................................................... 467

14.6.1 Rehabilitating Refractive Errors .................................... 468

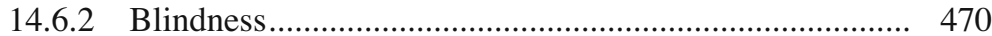

14.7 Speech Rehabilitation ................................................................. 472

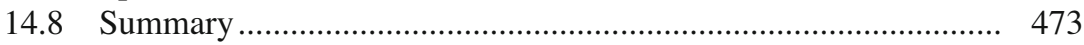

14.9 Foundation Concepts ……………………….............................. 474

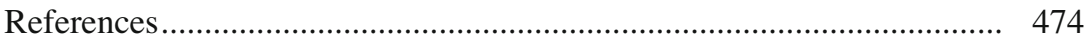

Appendix A: A Proposal to the National Institutes of Health

Under the Small Business Innovative Research Program.......................... 475

Appendix B: A Representative U.S. Patent ................................................ 483

Appendix C: An Informed Consent Form Used in a Human

Clinical Trial

Index 